\title{
Determinants of COVID-19 Vaccine Acceptance in Saudi Arabia: A Web-Based National Survey
}

This article was published in the following Dove Press journal:

Journal of Multidisciplinary Healthcare

\author{
Mohammed Al-Mohaithef $(\mathbb{D})^{1}$ \\ Bijaya Kumar Padhi $\mathbb{D}^{2}$ \\ 'Department of Public Health, College of \\ Health Sciences, Saudi Electronic \\ University, Riyadh, Saudi Arabia; \\ ${ }^{2}$ Department of Community Medicine \& \\ School of Public Health, Post Graduate \\ Institute of Medical Education and \\ Research (PGIMER), Chandigarh, India
}

Background: Vaccine hesitancy is a potential threat to global public health. Since there is an unprecedented global effort to develop a vaccine against the COVID-19 pandemic, much less is known about its acceptance in the community. Understanding key determinants that influence the preferences and demands of a future vaccine by the community may help to develop strategies for improving the global vaccination program. The aim of this study was to assess the prevalence of the acceptance of COVID-19 vaccine and their determinants among people in Saudi Arabia.

Methods: A web-based, cross-sectional study was conducted using snowball sampling strategy under a highly restricted environment. A bilingual, self-administered anonymous questionnaire was designed and sent to the study participants through social media plat-forms and email. Study participants were recruited across the country, including the four major cities (Riyadh, Dammam, Jeddah, and Abha) in Saudi Arabia. Key determinants that predict vaccine acceptance among respondents were modelled using logistic regression analysis. Of the 1000 survey invitees, 992 responded to the survey.

Results: Of the 992 respondents, 642 showed interest to accept the COVID-19 vaccine if it is available. Willingness to accept the future COVID-19 vaccine is relatively high among older age groups, being married participants with education level postgraduate degree or higher (68.8\%), non-Saudi (69.1\%), employed in government sector (68.9\%). In multivariate model, respondents who were above 45 years (aOR: 2.15; 95\% CI: 1.08-3.21) and married (aOR: 1.79; 95\% CI: $1.28-2.50)$ were significantly associated with vaccine acceptance $(\mathrm{p}<0.05)$.

Conclusion: Addressing sociodemographic determinants relating to the COVID-19 vaccination may help to increase uptake of the global vaccination program to tackle future pandemics. Targeted health education interventions are needed to increase the uptake of the future COVID-19 vaccine.

Keywords: coronavirus, COVID-19 vaccine, vaccine hesitancy, trust, perceived risk, Saudi Arabia

\section{Introduction}

The severe acute respiratory syndrome coronavirus 2 (SARS-CoV-2) pandemic, which is widely referred to as "COVID-19", has been infecting more than 5.5 million over 144 countries. $^{1-3}$ The pandemic poses a significant threat to the public health system, ${ }^{3,4}$ including catastrophic economic consequences around the world. Saudi Arabia has been plagued with several pandemics, including the Middle East Respiratory Syndrome Coronavirus (MERS-CoV), and the ongoing COVID-19 outbreak. ${ }^{5,6}$ As of 17 th October 2020, the virus has rapidly spread in the Kingdom, causing a total of 341,495 laboratory-confirmed cases with 5144 deaths. ${ }^{7}$ A vaccine is
Correspondence: Mohammed Al-Mohaithef Email m.almohaithef@seu.edu.sa 
considered to be the most awaiting intervention ${ }^{2,4,7}$ and hundreds of global R\&D institutions engaged in unprecedented speed to develop the vaccine ${ }^{7-11}$ However, public perception towards COVID-19 vaccine uptake is not available. Numerous studies have shown several factors responsible for vaccine acceptancy when a new vaccine is introduced. ${ }^{12-15}$ These include the safety and efficacy of the vaccine, adverse health outcomes, misconceptions about the need for vaccination, lack of trust in the health system, lack of knowledge among the community on vaccine-preventable diseases. ${ }^{15,16}$ Misinformation leading towards vaccine hesitancy could put public health at risk in responding to the current crisis.

In the previous pandemic like the H1N1 influenza A, when the vaccine was introduced, the acceptancy rate varied between $8 \%$ and $67 \% .{ }^{12}$ In the United States, the acceptance rate was reported to be $64 \% .{ }^{13}$ In the United Kingdom, $56.1 \%$ of the study participants reported accepting the swine flu (influenza A H1N1v) vaccine. ${ }^{17}$ In Hong Kong, $50.5 \%$ of the study population intended to receive a future $\mathrm{A} / \mathrm{H} 7 \mathrm{~N} 9$ vaccine during the outbreak in 2014. ${ }^{18}$ In Beijing, China, $59.5 \%$ of the study participants who had heard of H7N9 were willing to accept a future influenza A (H7N9) Vaccine. ${ }^{8}$

Vaccine acceptance and demand are complex in nature and context-specific, varying across time, place, and perceived behavioral nature of the community. ${ }^{9-15}$ A study in Ireland showed that health care workers avoided seasonal influenza vaccination due to their misconception, efficacy, and trust in the vaccine. ${ }^{16}$ In China, demographics and public perceptions are the predictors of vaccination acceptance. ${ }^{8}$ In Hong Kong, anxiety level and vaccine history were the main predictors towards vaccine acceptancy. ${ }^{17}$ In the United States, perceived effectiveness of the vaccine, social influence, and health insurance was the key predictor towards acceptance of an influenza vaccine. ${ }^{18}$ Another study in the United States reported greater hesitancy associated with lower vaccine uptake and greater confidence associated with higher vaccine uptake. ${ }^{19}$ In the United Arab Emirates, a study investigates parent attitudes about childhood vaccines and reported only $12 \%$ of parents' hesitancy towards childhood vaccination. ${ }^{20}$ The study reported vaccine safety $(17 \%)$, side effects (35\%), and too many injections (28\%) are critical factors in vaccine hesitancy. ${ }^{20}$ Respondents who had a history of being vaccinated against seasonal flu were more likely to report their intention to be vaccinated. ${ }^{14,15}$
A systematic review highlighted the role of public trust in vaccine uptake and reported a dearth in the research of vaccine uptake based on public trust in lowand middle-income settings. ${ }^{12}$ Another review that investigated the general public's willingness to accept or decline a pandemic vaccine (H1N1) identified several key predictors like people's perceived risk of infection, the severity of the event, personal consequences, history of previous vaccination, and ethnicity. ${ }^{11}$ A recent study highlighted that equitable vaccination across all population groups is challenging due to the complex human behavior which changes over space and time, ${ }^{10}$ and a meta-analysis demonstrated behavioral health model like the "theory of planned behavior" in explaining vaccine hesitancy. ${ }^{13}$ Numerous studies urged to enhance tailored interventions and policies to increase vaccination uptake. $^{9-11,13,16,21}$

Few studies have explored the prevalence of COVID19 vaccine acceptance and their determinants. ${ }^{22,23}$ A study conducted among health care workers (HCWs) in China showed a high acceptance of COVID-19 vaccination among health care workers in comparison to the general population. ${ }^{23}$ Another study in the United States reported that only $20 \%$ intend to decline the COVID- 19 vaccine. ${ }^{22}$ Since vaccine acceptancy is context-specific and varies with geography, culture, and sociodemographic, we aimed to understand the public willingness of a future COVID-19 vaccine in Saudi Arabia.

\section{Methods}

\section{Study Design and Setting}

The cross-sectional survey was designed using Survey Monkey ${ }^{\circledR}$ platform and used a snowball sampling strategy. Study participants were recruited across the Kingdom of Saudi Arabia, including major cities (Riyadh, Dammam, Jeddah, and Abha), and other minor cities. The above cities were selected based on the geographical presence of the Saudi Electronic University, which enables the researcher to collect information during the highly restricted environment of COVID-19 pandemic. Initially, the study investigators shared the survey link in social media (Twitter, Whats App, Telegram channel) and through emails to their primary contacts (aged 18 and above). The primary participants were requested to roll out the survey further. On receiving and clicking the link, participants got auto directed to the informed consent page, followed by the survey questionnaires. 


\section{Study Sample}

From the previous literature review of vaccine hesitancy in the community, it is estimated that about $15 \%$ of the study participants showed hesitancy towards accepting a vaccine. We estimate that a sample size of 800 should give us $80 \%$ power at a confidence level of $95 \%$. Accounting for non-response, dropout, and subgroup analyses our final sample size was planned to be 1000 completed questionnaires from participants. The sample size was calculated using the formula $\mathrm{N}=\mathrm{Z} \alpha 2 \mathrm{P}(1-\mathrm{P}) / \mathrm{d} 2$, in which $\alpha=0.05$ and $Z \alpha=1.96$, and the estimated acceptable margin of error for proportion $\mathrm{d}$ is 0.1 . The survey was stopped when we received 1000 completed questionnaires.

\section{Questionnaire Development}

We conducted a literature review ${ }^{9,24-26}$ to identify key areas, and a draft questionnaire was devised. The draft questionnaire was in bilingual (Arabic and English) format and consisting sections on sociodemographic, knowledge and perception towards COVID-19, trust in the health system, and participants' willingness to accept the COVID-19 vaccine if it is available in future. We tried to keep the questionnaire as short in length so that it can be quick to complete, and easy to follow. Questionnaire's content and clarity was assessed by the public health experts working at the College of Public Health at Saudi Electronic University. The draft questionnaire was pilot tested. The final questionnaire was developed based on the Cronbach's alpha values $(>0.70){ }^{27}$ The questionnaire was self-administered. The participants were instructed to select one option from the list of responses (Yes/No/Not sure).

\section{Ethics Statement}

This study followed the principle of the Declaration of Helsinki 1995 (revised in 2013). Ethical approval was granted for the study by the institutional Research Ethics Committee (SEUREC-CHS20110) Saudi Electronic University, Riyadh, Kingdom of Saudi Arabia and consent was taken before participation in the study.

\section{Data Analysis}

Descriptive statistics were conducted to generate summary tables for study variables. A cross-tabulation analysis was performed to examine the distribution of intention to uptake COVID-19 vaccine with respondents' sociodemographic characteristics using chi-squared tests. Logistic regression models were employed using a priori hypothesis to tabulate odds ratios (OR) and their 95\% confidence intervals $(95 \% \mathrm{CI})$. All data analysis was performed using STATA 13.0. A two-tailed p-value $<0.05$ was considered statistically significant.

\section{Results}

Of 1000 survey invitees, 992 (99.2\%) provided the informed consent and returned the survey. Table 1 shows the summary statistics of the sociodemographic profile of the study participants. Most of the respondents 436 (43.9\%) were aged between 26 and 35 years, followed

Table I Sociodemographic Characteristics of the Study Population ( $\mathrm{N}=992)$

\begin{tabular}{|c|c|c|}
\hline \multicolumn{2}{|c|}{ Sociodemographic Characteristics } & \multirow{6}{*}{$\begin{array}{l}\text { n (\%) } \\
264(26.61) \\
436(43.95) \\
239(24.09) \\
53(5.04)\end{array}$} \\
\hline Age & & \\
\hline & $18-25$ & \\
\hline & $26-35$ & \\
\hline & $36-45$ & \\
\hline & Above 45 & \\
\hline \multirow[t]{3}{*}{ Gender } & & \\
\hline & Male & $339(34.17)$ \\
\hline & Female & $653(65.83)$ \\
\hline \multirow[t]{4}{*}{ Marital Status } & & \\
\hline & Married & $512(5 I .6 I)$ \\
\hline & Single & $421(42.44)$ \\
\hline & Separated/divorced/Widowed & $60(5.95)$ \\
\hline \multirow[t]{3}{*}{ Nationality } & & \\
\hline & Saudi & $814(82.06)$ \\
\hline & Non-Saudi & I 78 (I7.94) \\
\hline \multirow[t]{8}{*}{ City of Resident } & & \\
\hline & Riyadh & $455(45.87)$ \\
\hline & Dammam & $184(18.55)$ \\
\hline & Jeddah & $119(12.00)$ \\
\hline & Abha & $23(2.32)$ \\
\hline & Madina & $3 I(3.3 I)$ \\
\hline & Al-Ahsa & $32(3.23)$ \\
\hline & Other & $148(|4.9|)$ \\
\hline \multirow[t]{5}{*}{ Education } & & \\
\hline & Postgraduate & $199(20.06)$ \\
\hline & Graduate & $497(50.10)$ \\
\hline & Diploma & $153(15.42)$ \\
\hline & High School & $143(14.42)$ \\
\hline \multirow[t]{5}{*}{ Occupation } & & \\
\hline & Government & $428(43.15)$ \\
\hline & Private & $151(15.22)$ \\
\hline & Self-employed & $19(1.92)$ \\
\hline & Not working & 394 (39.72) \\
\hline
\end{tabular}


by $264(26.6 \%)$ aged $18-25$ years, 239 (24\%) aged 36-45 years, and $53(5 \%)$ were aged 45 years and above (Table 1). Of the 992 participants, $653(65.8 \%)$ were female, 512 (51.6\%) were married, majority 814 (82\%) of the study participants were Saudi nationality, 455 (45.8\%) were from Riyadh, 497 (50.1\%) completed graduate-level education, and 428 (43.1\%) reported working in a government sector (Table 1).

Table 2 shows bivariate associations between sociodemographic characteristics and intent to uptake the COVID-19 vaccine among respondents in Saudi Arabia. Of the 992 respondents, $642(64.7 \%)$ intended to uptake the hypothetical vaccine, only $70(7 \%)$ reported hesitancy towards the COVID-19 vaccine, and 280 (28.2\%) were reported "not sure" about their intention (Table 2). Of the 53 respondents who were aged 45 years and above, 42 (79.2\%) of them showed interest to uptake the vaccine if it is available. Of the 512 participants who were married, 355 (69.3\%) reported accepting the COVID-19 vaccination (Table 2).

Table 3 presents logistic regression analysis for sociodemographic prediction of intent to uptake the COVID-19 vaccine among respondents. In the multivariate model, respondents who were above 45 years are 2.15 times likely to accept the vaccine (aOR: 2.15 ; 95\% CI: $1.08-3.21$ ). Similarly, participants who were married are 1.79 times likely to accept the vaccination (aOR: 1.79; 95\% CI: 1.28-2.50).

Table 4 shows the logistic regression analysis for factors potentially associated with the intention to receive the COVID-19 vaccine among respondents. In the multivariate model adjusted for sociodemographic characteristics, participants who were concerned about acquiring infection with the COVID-19 virus were 2.13 (95\% CI: $1.35-3.85$ ) times likely to accept the COVID-19 vaccine compared with those who were not concerned with the infection. Participants, who trusted the health system were 3.05 (95\% CI: $1.13-4.92)$ times most likely to accept the vaccination than those who have reported no trust.

\section{Discussions}

Vaccination is considered one of the most outstanding public health inventions in the 21st century. However, its acceptancy is varied with space, time, social class, ethnicity, and contextual human behavior. ${ }^{9,10,12,13,28}$ Our study, first of its kind in Saudi Arabia, used a web-based self-administered questionnaire and collected responses across the Kingdom, including four major cities (Riyadh, Jeddah, Dammam, and Abha) and
Table 2 Bivariate Associations Between Sociodemographic Characteristics and Intent to Uptake Coronavirus Vaccine Among Respondents in Saudi Arabia (N=992)

\begin{tabular}{|c|c|c|c|c|}
\hline \multirow[t]{2}{*}{ Variables } & \multicolumn{4}{|c|}{$\begin{array}{l}\text { "If Vaccine Against Coronavirus is Available, } \\
\text { I Will Take It" }\end{array}$} \\
\hline & $\begin{array}{l}\text { Yes } \\
(n=642)\end{array}$ & $\begin{array}{l}\text { No } \\
(n=70)\end{array}$ & $\begin{array}{l}\text { Not Sure } \\
(\mathrm{n}=\mathbf{2 8 0})\end{array}$ & p-value \\
\hline \multicolumn{5}{|l|}{ Age } \\
\hline $18-25$ & $172(65.15)$ & $14(5.30)$ & 78 (29.55) & \\
\hline $26-35$ & $280(64.22)$ & $36(8.26)$ & $120(27.52)$ & 0.201 \\
\hline $36-45$ & $148(61.92)$ & $19(7.95)$ & $72(30.13)$ & \\
\hline Above 45 & $42(79.25)$ & I (I.89) & $10(18.87)$ & \\
\hline \multicolumn{5}{|l|}{ Gender } \\
\hline Male & $235(69.32)$ & $22(6.49)$ & $82(24.19)$ & 0.087 \\
\hline Female & $407(62.33)$ & $48(7.35)$ & $198(30.32)$ & \\
\hline \multicolumn{5}{|l|}{ Marital status } \\
\hline Single & $248(58.91)$ & $33(7.84)$ & $140(33.25)$ & \\
\hline Divorced/Widowed & $39(66.10)$ & $4(6.78)$ & $16(27.12)$ & 0.024 \\
\hline Married & $355(69.34)$ & $33(6.45)$ & $124(24.22)$ & \\
\hline \multicolumn{5}{|l|}{ Nationality } \\
\hline Saudi & $519(63.76)$ & $63(7.74)$ & $232(28.50)$ & \\
\hline Non-Saudi & $123(69.10)$ & $7(3.93)$ & $48(26.97)$ & 0.152 \\
\hline \multicolumn{5}{|l|}{ City of residence } \\
\hline Riyadh & $286(62.86)$ & $36(7.91)$ & $133(29.23)$ & \\
\hline Dammam & $113(61.41)$ & $10(5.43)$ & $61(33.15)$ & 0.323 \\
\hline Jeddah & $80(67.23)$ & $7(5.88)$ & $32(26.89)$ & \\
\hline Others & $163(69.66)$ & $17(7.26)$ & $54(23.08)$ & \\
\hline \multicolumn{5}{|l|}{ Highest education } \\
\hline High School & $88(61.54)$ & $10(6.99)$ & 45 (3I.47) & \\
\hline Diploma & 99 (64.7I) & $7(4.58)$ & 47 (30.72) & \\
\hline Graduate & $318(63.98)$ & $42(8.45)$ & 137 (27.57) & 0.472 \\
\hline Post Graduate & $137(68.84)$ & II (5.53) & 51 (25.63) & \\
\hline \multicolumn{5}{|l|}{ Current occupation } \\
\hline Not working & $242(61.42)$ & $29(7.36)$ & $123(31.22)$ & \\
\hline Private/Self-employed & $105(61.76)$ & II (6.47) & $54(31.76)$ & 0.145 \\
\hline Government & $295(68.93)$ & $30(7.01)$ & $103(24.07)$ & \\
\hline
\end{tabular}

some minor cities in the country. Of the 992 study participants, 642 (64.7\%) said "Yes" to uptake the COVID-19 vaccine, 70 (7.0\%) said "no" to uptake COVID-19 vaccine, and 280 (28.2\%) said "not sure" to uptake the COVID-19 vaccine if it is available. Further, being aged (45 years and above) (aOR: 2.15; 95\% CI: 1.08-3.21), and being married (aOR: 1.79; 95\% CI: $1.28-2.50$ ) are likely to accept the COVID-19 vaccine than their counterparts. Study participants' trust in the health system (aOR: 3.05; 95\% CI: $1.13-4.92$ ) and perceived risk of acquiring infection (aOR: 2.13; 95\% CI: 1.35-3.85) were found to be significant predictors in explaining acceptancy of the COVID-19 vaccine. 
Table 3 Logistic Regression Analysis for Sociodemographic Prediction of Intent to Uptake Coronavirus Vaccine Among Respondents in Saudi Arabia (N=992)

\begin{tabular}{|c|c|c|c|c|}
\hline \multirow[t]{2}{*}{ Variables } & \multicolumn{4}{|c|}{ "Intended to Uptake Coronavirus Vaccine" } \\
\hline & OR $[95 \% \mathrm{Cl}]$ & p-value & aOR $[95 \% \mathrm{Cl}]$ & p-value \\
\hline \multicolumn{5}{|l|}{ Age } \\
\hline $18-25$ & Ref & & Ref & \\
\hline $26-35$ & $0.96[0.69-1.32]$ & 0.803 & $0.87[0.38-1.56]$ & 0.612 \\
\hline $36-45$ & $0.86[0.60-1.25]$ & 0.453 & $0.95[0.48-1.44]$ & 0.216 \\
\hline Above 45 & $2.04[1.00-4.15]$ & 0.049 & $2.15[1.08-3.21]$ & 0.032 \\
\hline \multicolumn{5}{|l|}{ Gender } \\
\hline Male & Ref & & Ref & \\
\hline Female & $0.73[0.55-0.96]$ & 0.029 & $0.80[0.58-1.10]$ & 0.181 \\
\hline \multicolumn{5}{|l|}{ Marital status } \\
\hline Single & Ref & & Ref & \\
\hline Divorced/Widowed & $1.36[0.76-2.41]$ & 0.293 & $1.70[0.92-3.17]$ & 0.090 \\
\hline Married & $1.57[1.20-2.06]$ & 0.001 & $1.79[1.28-2.50]$ & 0.001 \\
\hline \multicolumn{5}{|l|}{ Nationality } \\
\hline Saudi & Ref & & Ref & \\
\hline Non-Saudi & $1.27[0.89-1.80]$ & 0.177 & 1.17 [0.79-1.74] & 0.425 \\
\hline \multicolumn{5}{|l|}{ City of residence } \\
\hline Riyadh & Ref & & Ref & \\
\hline Dammam & $0.94[0.66-1.33]$ & 0.733 & $0.96[0.66-1.40]$ & 0.869 \\
\hline Jeddah & $1.21[0.79-1.85]$ & 0.378 & $1.23[0.79-1.92]$ & 0.350 \\
\hline Others & $1.35[0.96-1.90]$ & 0.076 & $1.41[0.99-2.00]$ & 0.055 \\
\hline \multicolumn{5}{|l|}{ Highest education } \\
\hline High School & Ref & & Ref & \\
\hline Diploma & $1.14[0.71-1.83]$ & 0.572 & $1.06[0.63-1.78]$ & 0.801 \\
\hline Graduate & 1.11 [0.75-1.62] & 0.593 & $1.17[0.78-1.76]$ & 0.438 \\
\hline Post Graduate & $1.38[0.87-2.16]$ & 0.161 & $1.48[0.99-2.23]$ & 0.054 \\
\hline \multicolumn{5}{|l|}{$\begin{array}{l}\text { Current } \\
\text { occupation }\end{array}$} \\
\hline Not working & Ref & & Ref & \\
\hline Private/Self-employed & $1.01[0.70-1.46]$ & 0.939 & $1.10[0.73-1.66]$ & 0.634 \\
\hline Government & $1.39[1.04-1.85]$ & 0.024 & $1.47[0.97-2.23]$ & 0.063 \\
\hline
\end{tabular}

Though there have been limited studies to explore the intention to uptake the COVID-19 vaccine in the current crisis, our results are in agreement with study conducted in China, and in the United States. ${ }^{22,23}$ The Chinese study reported $72.5 \%$ of the general population's intention to uptake COVID-19 vaccine. ${ }^{23}$ And the study conducted in the United States reported $80 \%$ acceptance of the COVID19 vaccine among the study population. ${ }^{22}$ In our study, $64.7 \%$ of study participants showed interest in the uptake of the COVID-19 vaccine. Similar observations were made during the H1N1 pandemic. ${ }^{11}$

Some qualitative comparisons can be made with similar studies, like in a systematic review, the acceptance rate varied between $8 \%$ and $67 \%$ for the H1N1 influenza
Table 4 Logistic Regression Analysis for Factors Potentially Associated with the Intention to Receive Coronavirus Vaccine Among Respondents in Saudi Arabia ( $\mathrm{N}=992)$

\begin{tabular}{|c|c|c|c|c|}
\hline \multirow[t]{2}{*}{ Variables } & \multicolumn{4}{|c|}{ "Intended to Uptake Coronavirus Vaccine" } \\
\hline & OR $[95 \% \mathrm{Cl}]$ & p-value & aOR $[95 \% \mathrm{Cl}]$ & p-value \\
\hline \multicolumn{5}{|c|}{ Perceived risk } \\
\hline No & Ref & & Ref & \\
\hline Yes & $2.48[1.11-3.95]$ & 0.031 & $2.13[1.35-3.85]$ & 0.002 \\
\hline \multicolumn{5}{|c|}{ Trust in the health system } \\
\hline No & Ref & & Ref & \\
\hline Yes & $2.85[1.03-4.80]$ & 0.028 & $3.05[1.13-4.92]$ & 0.001 \\
\hline
\end{tabular}

Note: Adjusted for age, gender, education, nationality, city of residence, and occupation.

A pandemic vaccine. ${ }^{11}$ The acceptance rate was reported to be $64 \%$ in the United States, ${ }^{25} 56.1 \%$ in the United Kingdom, ${ }^{29} 59.5 \%$ in Hong Kong, ${ }^{17}$ and $59.5 \%$ in China. ${ }^{8}$ The systematic review also highlighted that there was no consistent association with participants' demographic variables (age and sex) with vaccine uptake behavior. ${ }^{11}$ However, in our study, old aged participants are more likely to accept COVID-19 vaccination than their counterparts (aOR: 2.15; 95\% CI: 1.08-3.21).

Numerous studies reported the perceived risk of becoming infected as a predictor towards intention behind vaccination. ${ }^{11,14,15,23}$ In our study, participants who had a higher perceived risk of being infected are 2.13 times more likely to be vaccinated than those having a lower perceived risk (aOR: 2.13; 95\% CI: 1.35-3.85). Studies have shown that a higher trust in the health system is associated with the utilization of preventive health services such as vaccination. ${ }^{19,30,31}$ In our study, odds of having greater trust in the health system were 3.05 times higher, reporting their intention to uptake the COVID-19 vaccine (aOR: 3.05 ; 95\% CI: 1.13-4.92).

Our study has several limitations; firstly, it is crosssectional, depicts a picture of the community response at the point of the study. We asked the respondents to report their intention to receive the COVID-19 vaccine if it is available in the future. A considerable number of study participants $(28.2 \%)$ reported "Not sure" about their intention to uptake the COVID-19 vaccination. The real intention could be different when the vaccine is available. ${ }^{14}$ It is interesting to study how the intention varies over time and the context in the study population. Secondly, study responses were recorded using a web-based self- 
administered survey, instead of a direct face-to-face interview. This may lead to potential bias in reporting their responses. Third, the current study did not explore the motivation behind the acceptance or barriers behind the hesitancy of the VOVID-19 vaccine. Another key limitation of the study is the snowball sampling strategy, which may not represent the true picture of study participants. However, during the study period (lockdown due to COVID-19) this was the only available method to collect the data from the study participants.

Despite the above limitations, our study is the first of its kind, with a representative sample size across the county demonstrated the population's intention to uptake the COVID-19 vaccine. Once the pandemic is over, we will explore many additional research questions, including vaccine promotion strategies, vaccine safety, vaccine referral/recommendations, cost (out of pocket expenditure), including the key motivation and barriers towards COVID-19 vaccination.

\section{Conclusion}

This is the first community-based study under a highly restricted environment that assessed the public's intent to accept the hypothetical COVID-19 vaccine in the Kingdom with a representative sample. The study participant has a good intention to accept the hypothetical vaccine and is in accordance with the previously reported figures. Participants' perceived risk and trust in the health system were found to be significant predictors towards the intention of the COVID-19 vaccine in the Kingdom. Further study should corroborate our findings with public health promotion interventions. Health education targeting various sociodemographic groups should be taken as a priority to increase the COVID-19 vaccine uptake behavior in the country, and elsewhere.

\section{Disclosure}

The authors report no conflicts of interest in this work.

\section{References}

1. Chakraborty C, Sharma AR, Sharma G, Bhattacharya M, Lee SS. SARS-CoV-2 causing pneumonia-associated respiratory disorder (COVID-19): diagnostic and proposed therapeutic options. Eur Rev Med Pharmacol Sci. 2020;24(7):4016-4026.

2. Saha RP, Sharma AR, Singh MK, et al. Repurposing drugs, ongoing vaccine, and new therapeutic development initiatives against COVID-19. Front Pharmacol. 2020;11. doi:10.3389/fphar.202 0.01258
3. Chakraborty C, Sharma AR, Bhattacharya M, Sharma G, Lee SS. The 2019 novel coronavirus disease (COVID-19) pandemic: a zoonotic prospective. Asian Pac J Trop Med. 2020;13(6):242.

4. Chakraborty C, Sharma AR, Sharma G, Bhattacharya M, Saha RP, Lee -S-S. Extensive partnership, collaboration, and teamwork is required to stop the COVID-19 outbreak. Arch Med Res. 2020;51 (7):728-730. doi:10.1016/j.arcmed.2020.05.021

5. Barry M, Ghonem L, Alsharidi A, et al. Coronavirus disease-2019 pandemic in the Kingdom of Saudi Arabia: mitigation measures and hospital preparedness. J Nat Sci Med. 2020;2.

6. Barry M, Al Amri M, Memish ZA. COVID-19 in the shadows of MERS-CoV in the Kingdom of Saudi Arabia. J Epidemiol Glob Health. 2020;10(1):1. doi:10.2991/jegh.k.200218.003

7. Bhattacharya M, Sharma AR, Patra P, et al. Development of epitopebased peptide vaccine against novel coronavirus 2019 (SARS-COV2): immunoinformatics approach. J Med Virol. 2020;92(6):618-631. doi: $10.1002 / j m v .25736$

8. Wu S, Su J, Yang P, et al. Willingness to accept a future influenza A (H7N9) vaccine in Beijing, China. Vaccine. 2018;36(4):491-497. doi:10.1016/j.vaccine.2017.12.008

9. Larson HJ, Jarrett C, Eckersberger E, Smith DMD, Paterson P. Understanding vaccine hesitancy around vaccines and vaccination from a global perspective: a systematic review of published literature, 2007-2012. Vaccine. 2014;32(19):2150-2159. doi:10.1016/j. vaccine.2014.01.081

10. Habersaat KB, Jackson C. Understanding vaccine acceptance and demand - and ways to increase them. Bundesgesundheitsblatt Gesundheitsforschung Gesundheitsschutz. 2020;63(1):32-39. doi:10.1007/s00103-019-03063-0

11. Wilson K, Nguyen HH, Brehaut H. Acceptance of a pandemic influenza vaccine: a systematic review of surveys of the general public. Infect Drug Resist. 2011;4:197. doi:10.2147/IDR.S23174

12. Larson HJ, Clarke RM, Jarrett $C$, et al. Measuring trust in vaccination: a systematic review. Hum Vaccin Immunother. 2018;14 (7):1599-1609. doi:10.1080/21645515.2018.1459252

13. Xiao X, Wong RM. Vaccine hesitancy and perceived behavioral control: a meta-analysis. Vaccine. 2020;38(33):5131-5138. doi:10.1016/j.vaccine.2020.04.076

14. Gidengil CA, Parker AM, Zikmund-Fisher BJ. Trends in risk perceptions and vaccination intentions: a longitudinal study of the first year of the H1N1 pandemic. Am J Public Health. 2012;102(4):672-679. doi:10.2105/AJPH.2011.300407

15. Setbon M, Raude J. Factors in vaccination intention against the pandemic influenza A/H1N1. Eur $J$ Public Health. 2010;20 (5):490-494. doi:10.1093/eurpub/ckq054

16. Halpin C, Reid B. Attitudes and beliefs of healthcare workers about influenza vaccination. Nurs Older People. 2019;31(2):32-39. doi:10.7748/nop.2019.e1154

17. Chan E-Y-Y, Cheng CK-Y, Tam GC-H, Huang Z, Lee PY. Willingness of future A/H7N9 influenza vaccine uptake: a cross-sectional study of Hong Kong community. Vaccine. 2015;33 (38):4737-4740. doi:10.1016/j.vaccine.2015.07.046

18. Abbas KM, Kang GJ, Chen D, Werre SR, Marathe A. Demographics, perceptions, and socioeconomic factors affecting influenza vaccination among adults in the United States. PeerJ. 2018;6:e5171. doi: $10.7717 /$ peerj. 5171

19. Quinn SC, Jamison AM, An J, Hancock GR, Freimuth VS. Measuring vaccine hesitancy, confidence, trust and flu vaccine uptake: results of a national survey of White and African American adults. Vaccine. 2019;37(9):1168-1173. doi:10.1016/j.vaccine.20 19.01.033

20. Alsuwaidi AR, Elbarazi I, Al-Hamad S, Aldhaheri R, Sheek-Hussein $\mathrm{M}$, Narchi H. Vaccine hesitancy and its determinants among Arab parents: a cross-sectional survey in the United Arab Emirates. Hum Vaccin Immunother. 2020;1-7. doi:10.1080/21645515.2020.1753439 
21. Eilers R, De Melker HE, Veldwijk J, Krabbe PFM. Vaccine preferences and acceptance of older adults. Vaccine. 2017;35 (21):2823-2830. doi:10.1016/j.vaccine.2017.04.014

22. Thunstrom L, Ashworth M, Finnoff D, Newbold S. Hesitancy Towards a COVID-19 Vaccine and Prospects for Herd Immunity. Available SSRN 3593098. 2020.

23. Fu C, Wei Z, Pei S, Li S, Sun X, Liu P. Acceptance and preference for COVID-19 vaccination in health-care workers (HCWs). medRxiv. 2020

24. Herzog R, Álvarez-Pasquin MJ, Díaz C, Del Barrio JL, Estrada JM, Gil Á. Are healthcare workers' intentions to vaccinate related to their knowledge, beliefs and attitudes? A systematic review. BMC Public Health. 2013;13(1):154. doi:10.1186/1471-2458-13-154

25. Horney JA, Moore Z, Davis M, MacDonald PDM. Intent to receive pandemic influenza A (H1N1) vaccine, compliance with social distancing and sources of information in NC, 2009. Timmer A ed. PLoS One. 2010;5(6):e11226. doi:10.1371/journal.pone.0011226

26. Karlsson LC, Lewandowsky S, Antfolk J, et al. The association between vaccination confidence, vaccination behavior, and willingness to recommend vaccines among Finnish healthcare workers. PLoS One. 2019;14 (10):e0224330. doi:10.1371/journal.pone.0224330
27. Bland JM, Altman DG. Statistics notes: Cronbach's alpha. BMJ. 1997;314(7080):572. doi:10.1136/bmj.314.7080.572

28. Cooper S, Schmidt B, Sambala EZ, et al. Factors that influence parents' and informal caregivers' acceptance of routine childhood vaccination: a qualitative evidence synthesis. Cochrane Database Syst Rev. 2019;(2).

29. Rubin G, Potts H, Michie S. The impact of communications about swine flu (influenza A H1N1v) on public responses to the outbreak: results from 36 national telephone surveys in the UK. Health Technol Assess (Rockv). 2010;14(34). doi:10.3310/hta14340-03

30. Musa D, Schulz R, Harris R, Silverman M, Thomas SB. Trust in the health care system and the use of preventive health services by older Black and White adults. Am J Public Health. 2009;99(7):1293-1299. doi:10.2105/AJPH.2007.123927

31. Harris KM, Maurer J, Kellermann AL. Influenza vaccine - safe, effective, and mistrusted. $N$ Engl J Med. 2010;363(23):2183-2185. doi:10.1056/NEJMp1012333
Journal of Multidisciplinary Healthcare

\section{Publish your work in this journal}

The Journal of Multidisciplinary Healthcare is an international, peerreviewed open-access journal that aims to represent and publish research in healthcare areas delivered by practitioners of different disciplines. This includes studies and reviews conducted by multidisciplinary teams as well as research which evaluates the results or conduct of such teams or healthcare processes in general. The journal

\section{Dovepress}

covers a very wide range of areas and welcomes submissions from practitioners at all levels, from all over the world. The manuscript management system is completely online and includes a very quick and fair peer-review system. Visit http://www.dovepress.com/testimonials. php to read real quotes from published authors. 